\title{
Correlation of Incidence of Microvascular and Macrovascular Complications in Indian Diabetic Versus Nondiabetic Females
}

\author{
Sudanshu Garg ${ }^{1} \quad$ Indrani Garre $\quad$ Beatrice Anne ${ }^{2}$ \\ ${ }^{1}$ Department of Cardiology, Nizam's Institute of Medical Sciences, \\ Hyderabad, Telangana, India \\ 2Department of Endocrinology, Nizam's Institute of Medical \\ Sciences, Hyderabad, Telangana, India \\ ${ }^{3}$ Department of General Medicine, Nizam's Institute of Medical \\ Sciences, Hyderabad, Telangana, India \\ Ind J Car Dis Wom 2019;4:184-189
}

\author{
Y. Sathyanarayana Raju ${ }^{3}$
}

\begin{abstract}
Address for correspondence Sudanshu Garg, MD, Department of Cardiology, Nizam's Institute of Medical Sciences, Hyderabad, India (e-mail: sudanshugarg90@gmail.com).
\end{abstract}

\begin{abstract}
Keywords

- microvascular complications

- macrovascular complications

- Indian population

- diabetic females

- nondiabetic females

Background There are 425 million people afflicted with diabetes in the World (IDF 2018). The most common cause of death among people with type 2 Diabetes Mellitus (DM) is cardiovascular nature. The relative risks for ischemic heart disease (IHD) and cerebrovascular disease (CVD) are 2- to 4-fold and 2- to 3-fold higher, respectively, than the risk in nondiabetic subjects. Since there is less data correlating the incidence of microvascular and macrovascular complications in Indian females with type 2 DM, this study has been conducted.

Aim To evaluate the occurrence of symptomatic cardiac disease among female patients with and without type $2 \mathrm{DM}$.

Material \& Methods The study was conducted from the outpatient department (OPD) of a tertiary care hospital in Hyderabad. Female patients with and without type 2 DM patients were selected for the study after taking informed consent. The study was approved by the Institutional Ethics Committee (IEC) and was conducted in the endocrinology department and general medicine department to eliminate the bias of cardiovascular symptoms. Patients were subjected to a clinical questionnaire and relevant clinical investigations were conducted. The results of the study were systematically selected and statistically analyzed.

The study included female patients with and without type 2 DM of age more than 18 years and excluded male patients, $n$, and female patients with diabetes of less than 18 years.

Results This was a case-control observational study and a total of 200 study subjects were enrolled from the patients who visited the OPD from 1st January 2018 to 31 st June 2018. The total population was divided into two groups, that is, case (DM) group and control (non-DM) group with 100 subjects, respectively, in each group. The cases were selected from the patients attending the endocrinology OPD and the controls belonged to the general medicine department in our institute. The average age in the case group (DM) was $55.65 \pm 10.07$ years, and the control (non-DM) group was $50.21 \pm 13.7$ years. The average duration of diabetes was 9.1 years; hypertension (HTN) was 6.83 years in the case group (DM) versus 3.5 years among the control (non-DM) group. Among all cases, $64 \%$ were found to be symptomatic for cardiovascular diseases.
\end{abstract}

published online

December 20, 2019
C2019 Women in Cardiology and Related Sciences
License terms

()(1) $\odot \circledast$ 
Nephropathy was seen in 18 diabetic cases versus 2 in nondiabetic cases and it was statistically significant $(p=0.000)$. Neuropathy was seen in $47 \%$ cases versus $18 \%$ in control group with statistical significance $(p=0.000)$. Retinopathy was seen in 6 diabetic cases versus 1 in nondiabetic cases with statistical significance $(p=0.052)$.

For cardiac symptoms (i.e., chest pain, dyspnea, and diaphoresis), statistical significance was not achieved between the cases and controls.

Conclusion The incidence of symptomatic cardiac disease was much more frequent than other microvascular complications of diabetes.

Hence, screening for the cardiac disease should be conducted at the time of detection of diabetes rather than on follow-up.

\section{Introduction}

Diabetes Mellitus (DM) is perhaps one of the oldest known diseases in human history. The first clinical description of diabetes dates back to 1500 B.C. in ancient Egyptian text in which it was described as a condition of "too great emptying of urine." Around the same time, some Indian physicians observed that urine from people with diabetes attracted ants and flies; they named the condition "madhumeha" or "honey urine." DM was identified by the Indian physicians Sushruta and Charaka in 4th century AD. However, the first complete clinical description of diabetes dates back to the 1st century $\mathrm{AD}$ by the ancient Greek physician Aretaeus of Cappadocia, who also noted the excessive amount of urine which passed through the kidneys. It was in the 1920s when Banting and Best first used insulin extract to treat a patient. However, even in today's era, clinically treating diabetes poses a tough challenge.

There are 425 million people with diabetes in the World (IDF 2018). ${ }^{1}$ The relative risks for ischemic heart disease (IHD) and cerebrovascular disease (CVD) are 2- to 4-fold and 2- to 3-fold higher, respectively, than the risk in nondiabetic subjects. Detection of IHD in females with type 2 DM also poses a significant problem.

DM persuades microvasculature pathognomonic changes by increasing the thickness of the capillary basement membrane, which includes retina, myocardium, arterioles in the glomeruli, skin, and muscle, leading to the diabetic microangiopathy development. By these members thickening, vessel function abnormality was induced, which eventually led to multiple clinical problems such as hypertension (HTN), tissue hypoxia, and delayed wound healing. In the same way, neovascularization developing from the vasa vasorum may interconnect macro and microangiopathy, predict platelet rupture, and promote atherosclerosis.

\section{Aims and Objectives}

To observe a correlation of incidence of microvascular and macrovascular complications in female patients with and without type 2 DM.

\section{Materials and Methods}

This study is a case-control observational study with a total of 200 study subjects. The subjects for the study were selected from the cases who visited the OPD during the period of 1 st January 2018 to 31st June 2018.

The study population fulfilling the below selection criteria were part of this study conducted for six months. The total population was divided into two groups, that is, case (DM) group and control (non-DM) group with 100 subjects, respectively.

\section{Case (DM) Group ( $n=100)$}

Inclusion criteria:

- Female patients

- More than 18 years. age

Exclusion criteria:

- Male patients

- Non-DM patients

\section{Control (non-DM) Group ( $\mathrm{n}=100)$}

Inclusion criteria:

- Female patients

- More than 18 years. age

Exclusion criteria:

- Male patients

- DM patients

We collected the data from all female patients who were attending our institute endocrinology OPD and general medicine OPD using the questionnaire which covers microvascular and macrovascular complications history. These typically include retinopathy, nephropathy, and neuropathy. The diagnosis of type 2 DM was determined based on American Diabetes Association (ADA) criteria.

\section{Results}

The average age in the casegroup(DM) was $55.65 \pm 10.07$ years., and the control (non-DM) group was $50.21 \pm 13.7$ years. 


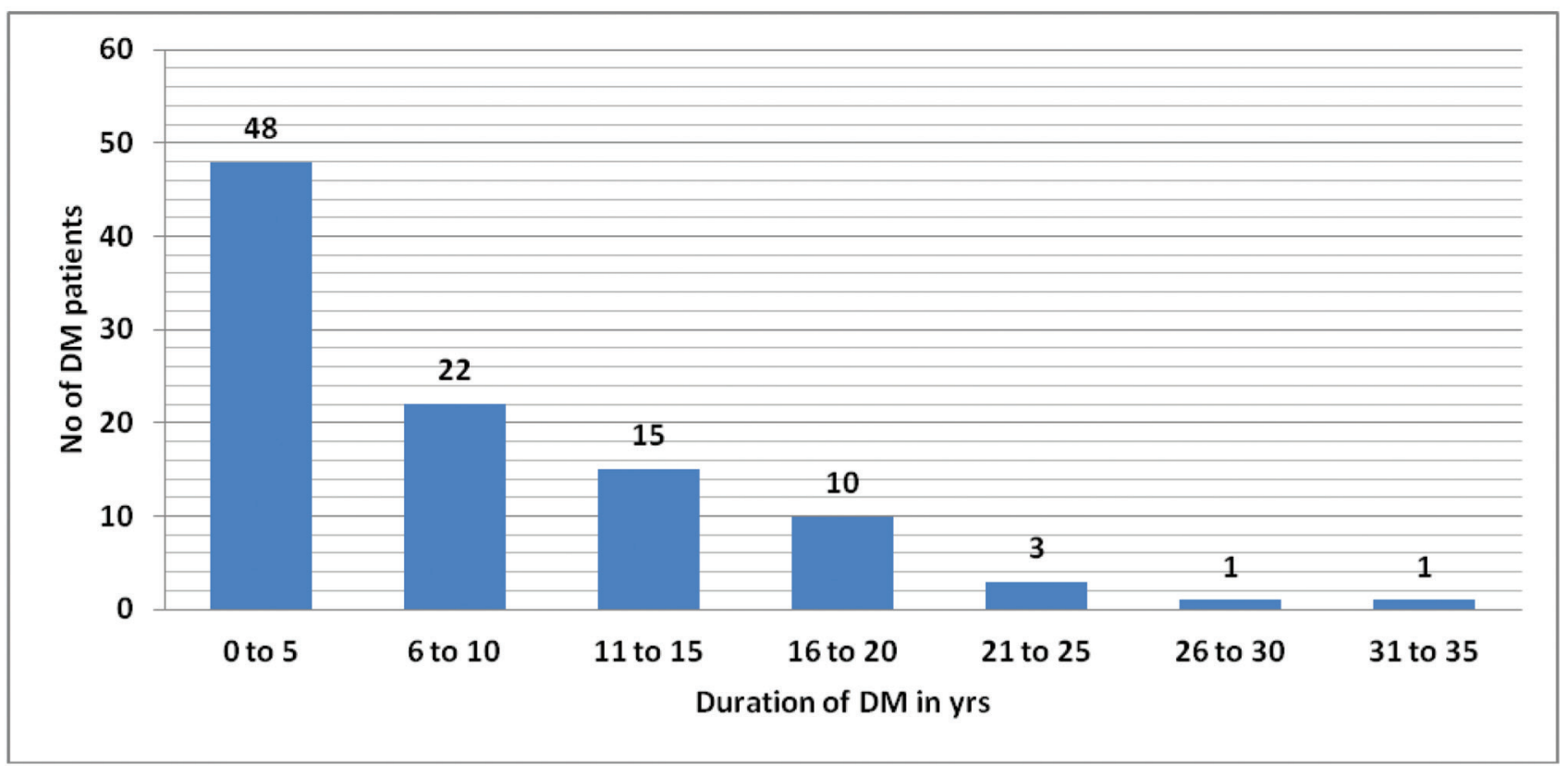

Fig. 1 Duration of diabetes.

The average duration of diabetes was 9.1 years ( - Fig. 1). The average duration of hypertension (HTN) was 6.83 years in the case group (DM) versus 3.5 years among the control (non-DM) group. Average HbA1c was $8.11 \%$ among the case group (DM) and 5.82 among the control (non-DM) group. The total demographic and biochemical parameters between the two groups are mentioned in - Table 1.

Nephropathy: Nephropathy was seen in 18 cases versus 2 in control. It was most commonly manifesting as overt proteinuria. The $p$-value for the same $(p=0.000)$ was statistically significant.

Neuropathy: Neuropathy was seen in $47 \%$ of cases versus $18 \%$ in control. P-value was 0.000 , which was statistically significant.

Retinopathy: Retinopathy was found in $6 \%$ of cases versus $1 \%$ of control. $P$-value was 0.052 , which was statistically significant.

Cardiac symptoms: Chest pain, dyspnea, palpitations, and diaphoresis occurred in equivalent frequency among the two groups. Statistical significance was not achieved.

The same has been illustrated in - Table 2 and - Fig. 2 .

Neuropathy and nephropathy were seen frequently among patients who had been diagnosed as diabetic for less than five years. (-Table 3) These complications are seen after more than 10 years of diabetes.

Hence, it is likely that many of these cases went undetected for many years despite being diabetic.

\section{Discussion}

DM is a known etiological factor for coronary artery diseases (CADs). DM inhibits the estrogen protection and increases the risk of a CAD 5.4 times more than in diabetes-free women. Cardiac death risk in women suffering from diabetes is three times greater than in those who do not. ${ }^{2}$
The detection of CAD in females with Type 2 DM is particularly tricky due to the atypical nature of symptoms found in females with Type 2 DM. ${ }^{3,4}$ In addition, more and more Indian women of younger age are being diagnosed as having Type 2 DM, particularly from rural areas. ${ }^{4,5}$ In a nation like India, where health systems are limited, and women are marginalized, they are very likely to ignore their symptoms and be ignored by the healthcare system.

Gestational diabetes mellitus (GDM) progresses to type 2 DM. Incidence of GDM is increasing; hence, type $2 \mathrm{DM}$ is increasing. ${ }^{6}$

Diabetes presents with both microvascular and macro vascular complications. Classically, retinopathy and neuropathy are known to occur by 5 years and nephropathy by 10 years after the onset of diabetes. CAD is common after 50 to 55 years of age but is seen in a younger age population due to diabetes. ${ }^{7}$ However, undetected and untreated diabetes would develop CADs and sudden cardiac death (SCD) sooner. This adds significantly to the disease adjusted life years (DALYs) of the patient and compromises life expectancy.

The most common symptom reported among females with type $2 \mathrm{DM}$ in our study was shortness of breath (SOB)/ fatigability (49\%). Chest pain and palpitations followed at $24 \%$ each, and the least common symptom was diaphoresis. Other studies show a similar prevalence of atypical chest pain and SOB among middle age to elderly women. ${ }^{8}$ Among the microvascular complications, peripheral neuropathy was the most common at $47 \%$, followed by nephropathy and retinopathy. Neuropathy ( $p=0.001)$, nephropathy ( $p=0.003)$, and retinopathy ( $p=0.052$ ) achieved statistical significance in our study. These may be useful in suspecting CAD in a new OPD patient found to be following type $2 \mathrm{DM}$.

Among all the cases, 64\% had suspected CAD. This is similar to results obtained in other studies. ${ }^{8}$ The average body 
Table 1 Baseline characteristics of groups

\begin{tabular}{|c|c|c|}
\hline \multirow[t]{2}{*}{ Variable } & \multicolumn{2}{|c|}{ Mean \pm SD } \\
\hline & $\begin{array}{l}\text { DM positive } \\
\text { (case) group }\end{array}$ & $\begin{array}{l}\text { DM negative } \\
\text { (control) group }\end{array}$ \\
\hline Age (yrs.) & $55.65 \pm 10.07$ & $50.21 \pm 13.70$ \\
\hline Height (cm) & $151.69 \pm 8.19$ & $158.85 \pm 4.30$ \\
\hline Weight (kg) & $66.87 \pm 11.65$ & $61.76 \pm 9.23$ \\
\hline Duration of DM (yrs.) & $9.18 \pm 7.32$ & - \\
\hline Duration of HTN (yrs.) & $6.83 \pm 5.9$ & $3.52 \pm 3.14$ \\
\hline Menopause Age (yrs.) & $46.61 \pm 5.6$ & $49.83 \pm 1.98$ \\
\hline Hysterectomy Age (yrs.) & $39.38 \pm 7.75$ & $42.42 \pm 5.82$ \\
\hline Maximum systolic blood pressure $(\mathrm{mmHg})$ & $148.38 \pm 26.13$ & $148.91 \pm 23.83$ \\
\hline Maximum diastolic blood pressure $(\mathrm{mmHg})$ & $84.52 \pm 11.12$ & $88.7 \pm 10.58$ \\
\hline Systolic blood pressure $(\mathrm{mmHg})$ & $129.35 \pm 18.7$ & $123.12 \pm 16.02$ \\
\hline Diastolic blood pressure $(\mathrm{mmHg})$ & $77.96 \pm 9.59$ & $78.37 \pm 7.09$ \\
\hline Heart rate (BPM) & $84.76 \pm 8.7$ & $82.47 \pm 9.54$ \\
\hline Hemoglobin (gms/L) & $13.92 \pm 15.05$ & $11.56 \pm 1.71$ \\
\hline Total leucocyte count (TLC) $\left(\mathrm{mm}^{3}\right)$ & $8499 \pm 2033$ & $7308 \pm 2857$ \\
\hline Blood urea (mg/dL) & $32.43 \pm 17.71$ & $22.6 \pm 8.04$ \\
\hline Serum creatinine $(\mathrm{mg} / \mathrm{dL})$ & $0.90 \pm 0.53$ & $0.78 \pm 0.45$ \\
\hline HbA1c & $8.11 \pm 2.21$ & $5.82 \pm 1.36$ \\
\hline Fasting blood sugar (FBS) & $163.11 \pm 80.02$ & $94.90 \pm 21.62$ \\
\hline Postprandial blood sugar (PPBS) & $230.61 \pm 86.12$ & $124.48 \pm 24.44$ \\
\hline Cholesterol (mg/dL) & $167.05 \pm 38.64$ & $191.14 \pm 21.58$ \\
\hline $\mathrm{LDL}(\mathrm{mg} / \mathrm{dL})$ & $84.97 \pm 36.21$ & $78.9 \pm 44$ \\
\hline Triglycerides (mg/dL) & $156.30 \pm 60.54$ & $191.14 \pm 21.58$ \\
\hline $\mathrm{HDL}(\mathrm{mg} / \mathrm{dL})$ & $44.47 \pm 13.81$ & $43.3 \pm 34.7$ \\
\hline VLDL (mg/dL) & $39.51 \pm 29.50$ & $41.33 \pm 24.11$ \\
\hline Vitamin D (ng/mL) & $22.19 \pm 14.83$ & $9.10 \pm 4.13$ \\
\hline
\end{tabular}

Table 2 Complications of DM

\begin{tabular}{|l|l|l|l|}
\hline Complaints & $\begin{array}{l}\text { DM positive } \\
\text { (case) group }(\boldsymbol{n}=100)\end{array}$ & $\begin{array}{l}\text { DM negative } \\
(\text { control) group } \\
(\boldsymbol{n}=100)\end{array}$ \\
\hline Nephropathy & $18(\%)$ & $2(2 \%)$ & 0.000 \\
\hline Retinopathy & $6(6 \%)$ & $1(1 \%)$ & 0.052 \\
\hline Neuropathy & $47(47 \%)$ & $18(18 \%)$ & 0.000 \\
\hline CAD & $21(21 \%)$ & $19(19 \%)$ & 0.724 \\
\hline Chest Pain & $24(24 \%)$ & $21(21 \%)$ & 0.611 \\
\hline Dyspnea & $49(49 \%)$ & $37(37 \%)$ & 0.084 \\
\hline Palpitations & $24(24 \%)$ & $15(15 \%)$ & 0.106 \\
\hline Diaphoresis & $15(15 \%)$ & $9(9 \%)$ & 0.190 \\
\hline Pedal Edema & $17(17 \%)$ & $11(11 \%)$ & 0.220 \\
\hline
\end{tabular}

mass index (BMI) in case group was 29.3, whereas in the control group, it was 24.4. So, a higher BMI was observed in the case group versus the control group. Higher BMI $(>25)$ is linked to a higher incidence of obstructive sleep apnea, CAD, HTN, and even SCD. ${ }^{9-13}$

Among the diabetic cases, there was no statistical difference in the incidence of chest pain, SOB, palpitation, and diaphoresis in the age group $<5$ years, 5 to 10 years, and $>10$ years. Hence, a baseline screening for cardiac disorders is required in all-female diabetic patients at the first point of detection of diabetes. ${ }^{13,14}$

Very few studies have evaluated the association of diabetes in Indian women and the incidence of cardiovascular diseases. ${ }^{4,5,14-16}$ We hope this study will help shed some light on 


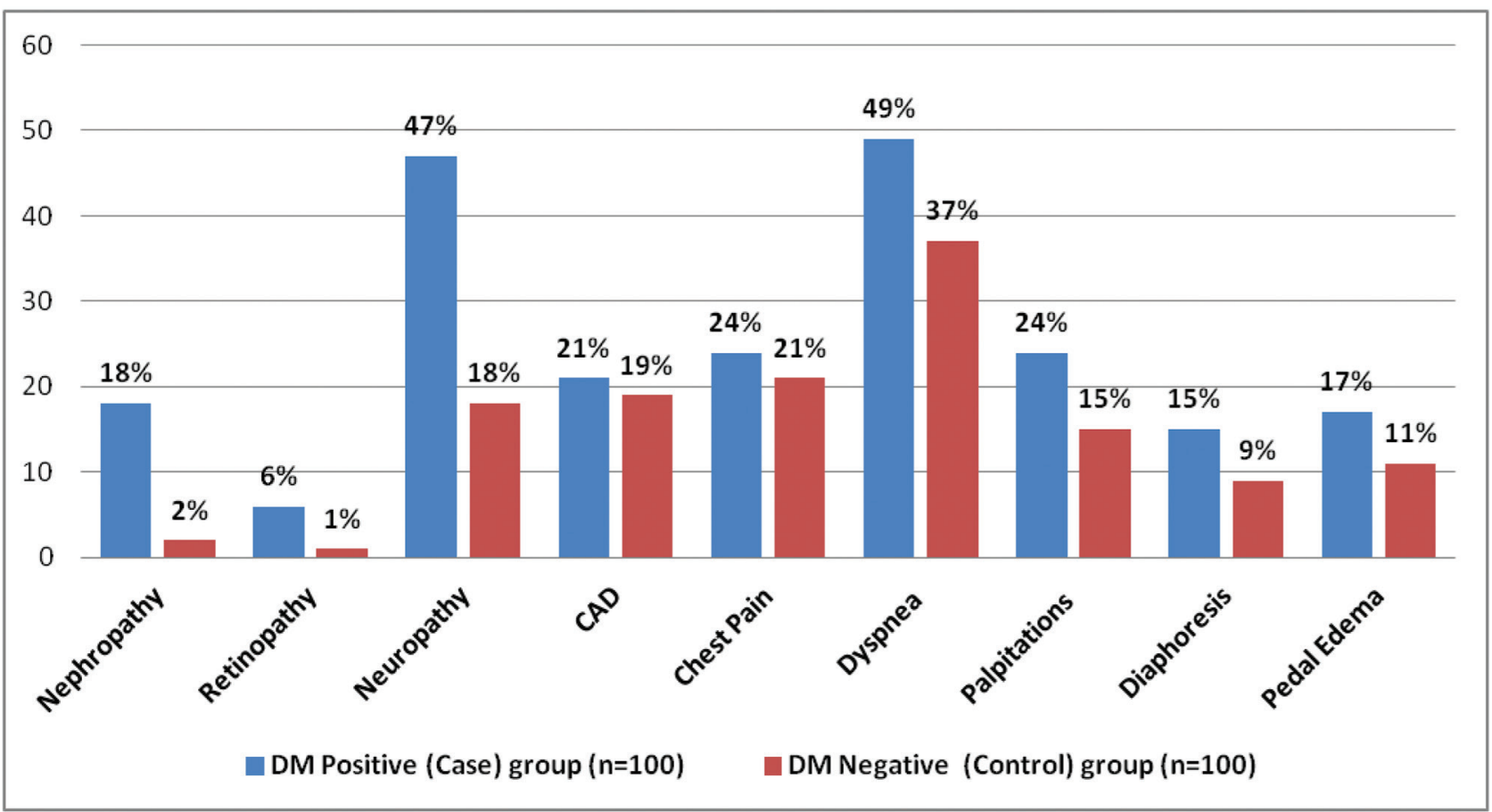

Fig. 2 Complications of DM.

Table 3 Incidence of complications in cases < 5yrs versus $>5$ years

\begin{tabular}{|l|l|l|l|}
\hline & DM $<5$ yrs & DM $>5$ yrs & $p$ value \\
\hline CAD & 8 & 13 & 0.535 \\
\hline Retinopathy & 1 & 5 & 0.132 \\
\hline Neuropathy & 20 & 27 & 0.784 \\
\hline Nephropathy & 6 & 12 & 0.301 \\
\hline
\end{tabular}

the same, enable earlier detection of diabetes, and promote cardiac evaluation of diabetic women.

\section{Limitation}

The results of this study need to be confirmed in a larger sample population. As the control group is nondiabetic, baseline characteristics are not completely matched.

\section{Conclusion}

The incidence of symptomatic cardiac disease was much more frequent than other complications in diabetic females. Hence, screening for cardiac disease should be conducted at the time of detection of diabetes rather than on follow-up.

\section{Conflict of Interest}

None.

\section{Acknowledgment}

We would like to thank Dr. Maddury Jyotsna, Professor Department of Cardiology, for her constant and invaluable support for this study.

\section{References}

1 International Diabetes Federation. IDF diabetes atlas 6th edn. Available at: https://www.idf.org/e-library/epidemiologyresearch/diabetes-atlas/19-atlas-6th-edition.html. Published 2013. Accessed November 18, 2019

2 Demissie S, Cupples LA, Shearman AM, et al. Estrogen receptor- $\alpha$. variants are associated with lipoprotein size distribution and particle levels in women: the Framingham Heart Study. Atherosclerosis 2006;185(1):210-218

3 Huxley R, Barzi F, Woodward M. Excess risk of fatal coronary heart disease associated with diabetes in men and women: meta-analysis of 37 prospective cohort studies. BMJ 2006;332(7533):73-78

4 Sridhar GR, Putcha V, Lakshmi G. Time trends in the prevalence of diabetes mellitus: ten year analysis from southern India (1994-2004) on 19,072 subjects with diabetes. J Assoc Physicians India 2010;58:290-294

5 Mohan V, Venkatraman JV, Pradeepa R. Epidemiology of cardiovascular disease in type 2 diabetes: the Indian scenario. J Diabetes Sci Technol 2010;4(1):158-170

6 Siddiqui S, Waghdhare S, Panda M, et al. Regional prevalence of gestational diabetes mellitus in North India. J Diabetol 2019;10:25-28

7 Nathan DM; DCCT/EDIC Research Group. The diabetes control and complications trial/epidemiology of diabetes 
interventions and complications study at 30 years: overview. Diabetes Care 2014;37(1):9-16

8 Hemingway H, Langenberg C, Damant J, Frost C, Pyörälä K, Barrett-Connor E. Prevalence of angina in women versus men: a systematic review and meta-analysis of international variations across 31 countries. Circulation 2008;117(12):1526-1536

9 Bello N, Mosca L. Epidemiology of coronary heart disease in women. Prog Cardiovasc Dis 2004;46(4):287-295

10 Choy B, Hansen E, Moss AJ, McNitt S, Zareba W, Goldenberg I; Multicenter Automatic Defibrillator Implantation Trial-II Investigators. Relation of body mass index to sudden cardiac death and the benefit of implantable cardioverter-defibrillator in patients with left ventricular dysfunction after healing of myocardial infarction. Am J Cardiol 2010;105(5):581-586

11 Chiuve SE, Sun Q, Sandhu RK, et al. Adiposity throughout adulthood and risk of sudden cardiac death in women. JACC Clin Electrophysiol 2015;1(6):520-528
12 Bhaskaran K, Dos-Santos-Silva I, Leon DA, Douglas IJ, Smeeth L. Association of BMI with overall and cause-specific mortality: a population-based cohort study of 3.6 million adults in the UK. Lancet Diabetes Endocrinol 2018;6(12):944-953

13 Vestberg D, Rosengren A, Eeg-Olofsson K, et al. Body mass index as a risk factor for coronary events and mortality in patients with type 1 diabetes. Open Heart 2018;5(1):e000727

14 Nuttall FQ. Body mass index: obesity, BMI, and health: a critical review. Nutr Today 2015;50(3):117-128

15 Chopra S, Peter S. Screening for coronary artery disease in patients with type 2 diabetes mellitus: an evidence-based review. Indian J Endocrinol Metab 2012;16(1):94-101

16 Mohan V, Shanthirani S, Deepa R, Premalatha G, Sastry NG, Saroja R; Chennai Urban Population Study (CUPS No. 4). Intra-urban differences in the prevalence of the metabolic syndrome in southern India - the Chennai Urban Population Study (CUPS No. 4). Diabet Med 2001;18(4):280-287 